\title{
Effects of cinnamon extract on complications of treatment and eradication of Helicobacter pylori in infected people
}

\author{
Ghazal Imani $^{1^{\circledR}}$, Alireza Khalilian ${ }^{2}$, Dara Dastan $^{3}{ }^{\circledR}$, Behzad Imani $^{4^{\oplus}}$, Maryam Mehrpooya $^{3^{*}}$ \\ ${ }^{1}$ School of Pharmacy, Hamadan University of Medical Sciences, Hamadan, Iran \\ ${ }^{2}$ Department of Gastroenterology and Hepatology, School of Medicine, Hamadan University of Medical Sciences, Hamadan, Iran \\ ${ }^{3}$ Department of Pharmacognosy, School of Pharmacy, Medicinal Plants and Natural Products Research Center, Hamadan University of Medical \\ Sciences, Hamadan, Iran \\ ${ }^{4}$ Department of Operating Room, School of Paramedicine, Hamadan University of Medical Sciences, Hamadan, Iran \\ ${ }^{5}$ Department of Clinical Pharmacy, School of Pharmacy, Medicinal Plants and Natural Products Research Center, Hamadan University of Medical \\ Sciences, Hamadan, Iran
}

\section{AR T I C L E IN F O}

\section{Article Type:}

Original Article

\section{Article History:}

Received: 31 July 2019

Accepted: 2 October 2019

\section{Keywords:}

Cinnamon

Helicobacter pylori

Disease eradication

Complicity

Peptic ulcer

\begin{abstract}
A B S T R A C T
Introduction: Treatment of Helicobacter pylori has various side effects like antibiotic resistance. The purpose of this study was to evaluate the effects of cinnamon extract on complications of treatment and eradication of $H$. pylori in infected people.

Methods: In this randomized clinical trial, a total of 98 eligible healthy and $H$. pylori-infected patients approved by esophageal endoscopy were selected. The cinnamon group received multidrug treatment including clarithromycin, amoxicillin and pantoprazole as well as a cinnamon extract capsule. The control group received multi-drug treatment and a $40 \mathrm{mg}$ starch capsule. In order to analyze the cinnamon extract efficacy, the urea breath test (UBT) was performed 3 months after the start of treatment. Clinical symptoms were evaluated by a questionnaire at the beginning (day of 0 ), 7 days and 14 days after starting treatment.

Results: The clinical symptoms such as nausea, vomiting, diarrhea, constipation, blurred vision, headache, metallic flavor, epigastric pain, burp, and appetite were significantly reduced in cinnamon group $(P<0.05)$. The odds ratio exhibited a higher eradication rate of $H$. pylori in cinnamon group $(73.47 \%$ in cinnamon group compared to $53.06 \%$ in the control group) $(P=0.036)$.

Conclusion: Cinnamon as assisted therapy is able to alleviate the disease and reduce the complications of $H$. pylori treatment.
\end{abstract}

Implication for health policy/practice/research/medical education:

The use of assisted therapy such as cinnamon increases $H$. pylori eradication rate and reduces the related side effects. The cinnamon extract might be recommended to physicians as adjunctive therapy for treatment of $H$. pylori infection.

Please cite this paper as: Imani G, Khalilian A, Dastan D, Imani B, Mehrpooya M. Effects of cinnamon extract on complications of treatment and eradication of Helicobacter pylori in infected people. J Herbmed Pharmacol. 2020;9(1):55-60. doi: 10.15171/ jhp.2020.08.

\section{Introduction}

Gastritis or stomach inflammation is a common digestive disorder caused by destruction of gastric mucosal layer (1). Helicobacter pylori infection and non-steroidal antiinflammatory drugs are known as two important causes of mucosal lesions in the stomach and duodenum (2). $H$. pylori infection is considered as one of the most commonly occurring infectious diseases in humans (3). The prevalence of $H$. pylori infection has been reported $80 \%$ and $30 \%-40 \%$ in developing and developed countries, respectively, and $68.3 \%$ in Iran (4). Eventually, this type of infection leads to chronic gastritis, peptic ulcer, and gastric cancer (5). One of the non-invasive diagnostic methods in H. Pylori infection is urea breath test (UBT) (6). Due to the increased resistance to antibiotics, the therapeutic regimen for the treatment of $H$. pylori is always determined as a multi-drug strategy. The usual treatment for $90 \%$ eradication of $H$. pylori is a triple-treatment or standard treatment of clarithromycin, metronidazole or amoxicillin, and a proton pump inhibitor for over 2 weeks administration (7). Multidisciplinary therapies have several side effects, such as oral metallic taste, 
increased light sensitivity, constipation, diarrhea, seizure, and polyneuropathy. $H$. pylori easily become resistant to clarithromycin and metronidazole. On the other hand, these antibiotics cannot be used again after a course of treatment (8). Due to antibacterial and anti-inflammatory properties, cinnamon is used as complementary medicine besides the multi-drug treatment. In recent years, much attention has been paid to herbal remedies in treatment of $H$. pylori. The antimicrobial effects of many plant species on $H$. pylori have been studied, including green tea, black tea, thymes (9), Origanum majorana, garlic (10), Glycyrrhiza glabra (11), Salvia officinalis, Myrtus, wormwood, Mentha, Achillea millefolium, Chamomile and Rosemary (3,12). Cinnamon is the dried skin of different species of Cinnamomum and a member of Lauraceae family. Cinnamon contains $0.5 \%-2.5 \%$ essential oil and nutritional components like cinnamoyl amoic acid, eugenol, transaminase, and polyethylene compounds including hydroxycinnamic aldehyde, ortho-tetracycline aldehyde, cinnamyl alcohol and acetate, and also terpene compounds such as limonene, alfatripenols, tannins, and oligomeric svidinids such as tinan cyanine and even mucilage derivatives (glucan) such as synizilanol (13). Cinnamon has acceptable antimicrobial and antifungal effects due to the presence of ortho-methoxy cinamine aldehyde $(3,13)$. According to drug resistance and side effects of multi-drug therapy as well as anti-bacterial and anti-inflammatory effects of cinnamon $(14,15)$, this study was designed to evaluate the effects of cinnamon extract on treatment of $H$. pylori infection.

\section{Materials and Methods}

Study group

This simple double-blind clinical trial study was conducted at the gastrointestinal department of Shahid Beheshti hospital, Hamadan, Iran in 2019. The H. pylori-infected patients' age ranged from 18 to 80 years. The sample size was 49 patients for each cinnamon and control groups (totally 98 cases). H. pylori infection was confirmed by endoscopy and biopsy procedures.

Inclusion and exclusion criteria and data collection The presence of clinical symptoms such as dyspepsia, nausea, vomiting and heartburn, and the absence of drug sensitivity, pregnancy and lactation were considered as inclusion criteria. Exclusion criteria were considered the presence of possible side effects, intolerance to the treatment, and incidence of pregnancy during the study. The demographic data were collected by clinical information questionnaire.

Experimental treatments

Patients were under treat with multiple drug medication, including clarithromycin $500 \mathrm{mg}$, amoxicillin $1 \mathrm{~g}$, and pantoprazole $20 \mathrm{mg}$. In addition to the previous drugs, the cinnamon extract was given in the form of $40 \mathrm{mg}$ capsule for cinnamon group and $40 \mathrm{mg}$ starch capsule for the control group. All medications were administrated twice daily. The UBT was hired three months after treatment in order to assess the efficacy of cinnamon extract application. Complications such as nausea, vomiting, diarrhea, constipation, blurred vision, headache, metallic flavor, epigastric pain, heartburn, skin rash, flatus, burp, and reduced appetite were studied at 0,7 and 14 days after treatment.

\section{Statistical analysis}

Data were analyzed by chi-square, Fisher exact, $t$ test, and reduction rate tests using SPSS software (version 23). $P$ $<0.05$ was considered as statistically significant.

\section{Results}

According to the demographic information presented in Table 1 , the highest age $(\geq 50)$ was observed in both groups of cinnamon (28.5\%) and control (34.8\%) groups. The percentage of female subjects existed in two groups of cinnamon and control groups were $57.2 \%$ and $59.2 \%$, respectively. The highest level of education in two groups was diploma (38.8\% in cinnamon group and $42.8 \%$ in the control group). People with height of 169-160 cm included the largest number of people available in this investigation (36.8\% in cinnamon group and $42.8 \%$ in the control group). The highest weight of patients in cinnamon group was $\geq 80 \mathrm{~kg}$ and comprised $28.8 \%$ of the population. Also, the highest weight in the control group was $60-69 \mathrm{~kg}$ and comprised $34.7 \%$ of the population. The highest scale of body mass index (BMI) in both groups was $20-25 \mathrm{~kg} / \mathrm{m}^{2}$ which included $42.8 \%$ and $40.8 \%$ of population in cinnamon and control groups, respectively. The most common blood type was $\mathrm{O}^{+}$in cinnamon group (59.1\%) and control group (57.1\%). In the $81.6 \%$ of cinnamon group and $83.7 \%$ of members in the control group, the experience of smoking was not recorded. Also the experience of ulcer was found $79.6 \%$ and $77.5 \%$ in cinnamon and control groups, respectively.

The results also showed that the frequency and percentage of treatment complications in eradication rate of $H$. pylori in both groups of cinnamon and control were decreased significantly at the days of 0,7 and at the end of the study (day 14) including nausea $(P=0.032)$, vomiting $(P=0.049)$, blurred vision $(P=0.03)$, metallic flavor ( $P=0.01)$, heartburn $(P=0.045)$, epigastric pain $(P=0.02)$, flatus $(P=0.047)$, and also appetite loss $(P=0.01)$ (Table 2$)$.

Negative test for UBT $H$. pylori was $73.47 \%$ in the cinnamon group and $53.06 \%$ in the control group $(P=0.036) \quad($ Table 3).

\section{Discussion}

The study aimed to evaluate the effects of cinnamon extract as an adjuvant on $H$. pylori eradication. In this 
Table 1. Demographic information at the beginning of the study

\begin{tabular}{|c|c|c|c|c|c|c|}
\hline \multirow{2}{*}{\multicolumn{2}{|c|}{ Demographic information }} & \multicolumn{2}{|c|}{ Cinnamon group } & \multicolumn{2}{|c|}{ Control group } & \multirow{2}{*}{$P$ value } \\
\hline & & \multirow{2}{*}{$\frac{\text { No. }}{4}$} & \multirow{2}{*}{$\begin{array}{c}\% \\
8.2\end{array}$} & \multirow{2}{*}{$\frac{\text { No. }}{4}$} & \multirow{2}{*}{$\begin{array}{c}\% \\
8.2\end{array}$} & \\
\hline \multirow{5}{*}{ Age } & $<20$ & & & & & \multirow{5}{*}{0.742} \\
\hline & $20-29$ & 10 & 20.4 . & 7 & 14.3 & \\
\hline & $30-39$ & 10 & 20.4 & 9 & 18.3 & \\
\hline & $40-49$ & 11 & 22.5 & 12 & 24.4 & \\
\hline & $\geq 50$ & 14 & 28.5 & 17 & 34.8 & \\
\hline \multirow{2}{*}{ Sex } & Male & 21 & 42.8 & 20 & 40.8 & \multirow{2}{*}{0.981} \\
\hline & Female & 28 & 57.2 & 29 & 59.1 & \\
\hline \multirow{4}{*}{ Education } & Illiterate & 11 & 22.5 & 13 & 26.5 & \multirow{4}{*}{0.538} \\
\hline & Under diploma & 10 & 20.4 & 8 & 16.3 & \\
\hline & Diploma & 19 & 38.8 & 21 & 42.8 & \\
\hline & Academic & 9 & 18.4 & 7 & 14.4 & \\
\hline \multirow{4}{*}{ Height } & $<160$ & 9 & 18.4 & 6 & 12.2 & \multirow{4}{*}{0.821} \\
\hline & $160-169$ & 18 & 36.8 & 21 & 42.8 & \\
\hline & $170-179$ & 15 & 30.6 & 16 & 32.7 & \\
\hline & $\geq 180$ & 7 & 14.3 & 6 & 12.2 & \\
\hline \multirow{4}{*}{ Weight } & $<60$ & 9 & 18.4 & 8 & 16.3 & \multirow{4}{*}{0.753} \\
\hline & $60-69$ & 14 & 28.6 & 17 & 34.7 & \\
\hline & $70-79$ & 12 & 24.4 & 11 & 22.4 & \\
\hline & $\geq 80$ & 14 & 28.6 & 13 & 26.5 & \\
\hline \multirow{4}{*}{ BMI } & $>20$ & 6 & 12.2 & 8 & 16.3 & \multirow{4}{*}{0.468} \\
\hline & $20-25$ & 21 & 42.8 & 20 & 40.8 & \\
\hline & $26-30$ & 19 & 38.8 & 18 & 36.8 & \\
\hline & $>30$ & 3 & 6.2 & 3 & 6.2 & \\
\hline \multirow{5}{*}{ Blood group } & $\mathrm{O}+$ & 29 & 59.1 & 28 & 57.1 & \multirow{5}{*}{0.990} \\
\hline & O- & 4 & 8.2 & 4 & 8.2 & \\
\hline & $A+$ & 5 & 10.2 & 6 & 12.2 & \\
\hline & $\mathrm{B}+$ & 7 & 14.3 & 8 & 16.3 & \\
\hline & $\mathrm{AB}+$ & 4 & 8.2 & 3 & 6.2 & \\
\hline \multirow{2}{*}{ Smoking } & Yes & 9 & 18.4 & 8 & 16.3 & \multirow{2}{*}{0.234} \\
\hline & No & 41 & 81.6 & 41 & 81.6 & \\
\hline \multirow{3}{*}{ Type of ulcer } & Gastric ulcer & 39 & 79.6 & 38 & 77.5 & \multirow{3}{*}{0.753} \\
\hline & Duodenal ulcer & 9 & 18.4 & 11 & 22.5 & \\
\hline & Both & 1 & 2 & 0 & 0 & \\
\hline
\end{tabular}

${ }^{a}$ Chi-square test.

study, there were no significant differences among the two groups regarding the demographic variables (age, sex, height, weight, BMI, smoking, blood type, and type of ulcer). Perri et al indicating that age and smoking were recognized as risk factors leading to $H$. pylori treatment failure (16). Also, the study of Homayoni showed that with age, the frequency of positive cases enhances. In the Homayoni investigation, the smoking was recognized as an interfering factor in the ulcer treatment, but the results of the present study showed no significant statically alteration (17). In the study of Camargo et al smoking failed the treatment of $H$. pylori infection, and the smoking cessation enhanced the treatment process (18). In the study of Silva et al no significant relation was reported between gender and smoking status. However, there was a significant failure in the treatment of older patients (19).

The obtained results from the present study indicated a significant reduction of therapeutic complications in cinnamon and control groups; such as nausea, vomiting, blurred vision, metallic flavor, heartburn, epigastric pain, flatus, and also appetite loss. The results of this study and the study of Nair et al showed that cinnamon consumption had fewer side effects (20). Unlike to this study, the Homayoni study reported that post-treatment complications were significantly similar in both groups, although the frequency of complications in the cinnamon group was less in comparison with the control group. In this study, the epigastric pain was seen as the most common factor in both groups, and also the frequency of diarrhea in the cinnamon group was lower than the control group (17). Medications with anti-inflammatory and antibacterial effects can employ as a supplement therapy in the treatment of $H$. pylori. Cinnamon with antibacterial and anti-inflammatory properties can be used as assisted therapy of $H$. pylori $(21,22)$. Hong et al in an in vivo study investigated the anti-inflammatory activity of cinnamon juice extract as well as in vitro models. They showed that cinnamon had a variety of pharmacological activities 
Table 2. Comparison of treatment complications in cinnamon and control groups

\begin{tabular}{|c|c|c|c|c|c|c|}
\hline $\begin{array}{l}\text { Complications of } \\
\text { treatment }\end{array}$ & Groups & $\begin{array}{l}\text { Frequency (percent) } \\
\text { at the beginning of } \\
\text { the study }\end{array}$ & $\begin{array}{l}\text { Frequency } \\
\text { (percent) at the } \\
\text { end of } 7^{\text {th }} \text { days }\end{array}$ & $\begin{array}{l}\text { Frequency } \\
\text { (percent) at the } \\
\text { end of } 14^{\text {th }} \text { days }\end{array}$ & $\begin{array}{l}\text { Frequency (percent) reduction rate } \\
\text { (between the beginning of the study } \\
\text { and end of } 14^{\text {th }} \text { days) }\end{array}$ & $P$ value \\
\hline \multirow{2}{*}{ Nausea } & Cinnamon & $15(30.6)$ & $12(24.48)$ & $4(8.16)$ & $11(73)$ & \multirow{2}{*}{0.032} \\
\hline & Control & $17(34.69)$ & $11(22.44)$ & $11(22.44)$ & $6(35)$ & \\
\hline \multirow{2}{*}{ Vomiting } & Cinnamon & 7 (14.9) & $3(6.12)$ & $1(2)$ & $6(85)$ & \multirow{2}{*}{0.049} \\
\hline & Control & $9(18.36)$ & $5(10.20)$ & $5(10.20)$ & $4(44)$ & \\
\hline \multirow{2}{*}{ Diarrhea } & Cinnamon & $8(16.32)$ & $3(6.12)$ & $4(8.16)$ & $4(50)$ & \multirow{2}{*}{0.06} \\
\hline & Control & $10(20.40)$ & $4(8.16)$ & $1(2)$ & $9(90)$ & \\
\hline \multirow{2}{*}{ Constipation } & Cinnamon & $11(22.44)$ & $8(16.32)$ & $6(12.24)$ & $5(45)$ & \multirow{2}{*}{0.1} \\
\hline & Control & $18(36.73)$ & $18(36.73)$ & 15 (30.16) & $3(16)$ & \\
\hline \multirow{2}{*}{ Blurred vision } & Cinnamon & $13(26.53)$ & $5(10.20)$ & $4(8.16)$ & $2(96)$ & \multirow[t]{2}{*}{0.03} \\
\hline & Control & 9 (18.36) & $12(24.48)$ & $7(14.28)$ & $2(22)$ & \\
\hline \multirow{2}{*}{ Headache } & Cinnamon & $20(40.81)$ & $9(18.36)$ & $6(12.24)$ & $4(20)$ & \multirow{2}{*}{0.24} \\
\hline & Control & 22 (44.89) & $16(32.65)$ & $14(28.57)$ & $6(83)$ & \\
\hline \multirow{2}{*}{ Metallic flavor } & Cinnamon & $22(44.89)$ & $15(30.6)$ & $6(12.24)$ & $16(73)$ & \multirow{2}{*}{0.01} \\
\hline & Control & 19 (38.77) & $23(46.93)$ & $26(53)$ & $-7(23)$ & \\
\hline \multirow{2}{*}{ Epigastric pain } & Cinnamon & 39 (79.59) & 22 (44.89) & $12(24.48)$ & $27(69)$ & \multirow{2}{*}{0.02} \\
\hline & Control & $43(87.75)$ & 29 (59.18) & $24(48.97)$ & $19(44)$ & \\
\hline \multirow{2}{*}{ Heartburn } & Cinnamon & $32(65.30)$ & $11(22.44)$ & $8(16.32)$ & $24(75)$ & \multirow{2}{*}{0.045} \\
\hline & Control & $34(69.38)$ & $19(32.65)$ & $15(26.53)$ & $19(60)$ & \\
\hline \multirow{2}{*}{ Skin rash } & Cinnamon & $9(18.36)$ & $1(2)$ & $1(2)$ & $8(88)$ & \multirow{2}{*}{0.87} \\
\hline & Control & $15(30.6)$ & $2(4)$ & $2(4)$ & $13(86)$ & \\
\hline \multirow{2}{*}{ Flatus } & Cinnamon & $27(55.10)$ & $20(40.81)$ & $13(26.53)$ & $14(52)$ & \multirow{2}{*}{0.047} \\
\hline & Control & $31(63.26)$ & $23(46.93)$ & $20(40.81)$ & $11(35)$ & \\
\hline \multirow{2}{*}{ Burp } & Cinnamon & $27(55.10)$ & $14(28.57)$ & $11(22.44)$ & $16(59)$ & \multirow{2}{*}{0.09} \\
\hline & Control & $32(65.30)$ & $23(46.93)$ & $20(40.81)$ & $12(37)$ & \\
\hline \multirow{2}{*}{ Reduced appetite } & Cinnamon & $16(32.65)$ & $11(22.44)$ & $9(18.36)$ & $7(43)$ & \multirow{2}{*}{0.01} \\
\hline & Control & 17 (34.69) & $16(32.65)$ & $16(32.65)$ & $1(1)$ & \\
\hline
\end{tabular}

Table 3. Comparison of treatment efficacy based on urea breath test (UBT) at the study of the effects of cinnamon extract on complications of treatment and eradication of Helicobacter pylori in infected people

\begin{tabular}{lcc}
\hline Variable & Frequency and percentage of UBT & Frequency and percentage of UBT $^{+}$ \\
\hline Cinnamon & $36(73.47 \%)$ & $13(26.53 \%)$ \\
Control & $26(53.06 \%)$ & $23(46.94 \%)$ \\
\hline
\end{tabular}

${ }^{\mathrm{a}}$ Chi-square test.

including anti-inflammatory, antibacterial, antiviral and anti-cancer properties. In the study of Hang et al, following oral administration of cinnamon to mice, the serum levels of TNF- $\alpha$ and IL- 6 were significantly reduced. This anti-inflammatory effect may be due to the presence of polyphenols in the cinnamon extract (23). Durak et al study showed that cinnamon had anti-inflammatory and antioxidant activity and was able to eliminate free radicals and inhibit lipoxygenase activity $(14,24)$. Zaidi et al investigated the indigenous medicinal plants of Pakistan such as cinnamon can be used to treat peptic ulcer and gastric cancer (25).

The effectiveness of $H$. pylori treatment with UBT is assessed by measuring the odds ratio. The results of this study showed that prescription of $40 \mathrm{mg}$ powder of cinnamon extract twice a day causes a significant negative UBT in cinnamon group (73.47\%) and the control group (53.06\%) $(P=0.036)$. The odds ratio of the $H$. pylori symptoms in cinnamon group was 2.45 times higher than the control group. In the study of Homayoni, the fecal antigen test was $67 \%$ and $55 \%$ negative in cinnamon and control groups, respectively. These results indicated that the consumption of cinnamon powder had therapeutic effects on $H$. pylori infected patients (17). It should be noted that in the Homayoni study the fecal antigene test has been used to evaluate the eradication of $H$. pylori while in the present study, the UBT has been used to evaluate the eradication of $H$. pylori. In the study of Shafaghi-Asl et al with the aim of comparison of the effects of water and ethanol extracts of Curcuma longa and cinnamon on the 
in-vitro growth of $H$. pylori, showed that both plants had antibacterial properties (26). Pakbaz et al investigated the effects of 10 medicinal herbs, including cinnamon against $H$. pylori. All H. pylori isolated strains were sensitive to gentamicin, tetracycline, and ciprofloxacin (27). Ranjbaran et al investigated the antibacterial effect of 4 plant extracts of cinnamon, black cumin, fennel and lemon on $H$. pylori by disc diffusion and flow cytometry techniques. The results indicate that among 14 strains of $H$. pylori, $49.9 \%$ of the strains were susceptible to cinnamon extract. In general, the mentioned study showed that all four herbal extracts had antibacterial effects on $H$. pylori (3).

\section{Conclusion}

Cinnamon is a medicinal plant with antibacterial and antiinflammatory effects which can reduce the complications of $H$. pylori treatment and increase the efficacy of antibiotics.

\section{Acknowledgment}

This study was a part of the thesis for the Degree of Doctoral in Pharmacy. We would like to acknowledge the financial support of the study by the Research Administration of the School of Pharmacy, Hamadan University of Medical Sciences. Authors are thankful for the patients who participated in the research.

\section{Authors' contribution}

Study design: GhI, MM, ArKh, DD, BI; data collection: GhI, MM, ArKh; data analysis: GhI, MM, ArKh, DD, BI; manuscript preparation: GhI, MM, ArKh, DD, BI; final approval: GhI, MM, ArKh, DD, BI.

\section{Conflict of interests}

There was no conflict of interest to declare by the authors.

\section{Ethical considerations}

The project was approved by the ethics committee in research with the number of IR.UMSHA.REC.1397.135 and was registered in the Iranian Center for Clinical Trial with the identifier number of IRCT20121114011469N3.

\section{Funding/Support}

This study was financially supported by the Research Administration of Hamadan University of Medical Sciences, Hamadan, Iran (Grant Number 9706133486).

\section{References}

1. Makobongo MO, Gilbreath JJ, Merrell DS. Nontraditional therapies to treat Helicobacter pylori infection. J Microbiol. 2014;52(4):259-72. doi: 10.1007/s12275-014-3603-5.

2. Sayehmiri K, Tavan H. Prevalence of peptic ulcer in Iran using the meta-analysis and systematic review. Govaresh. 2016;20(4):250-8. [Persian].

3. Ranjbarian P, Sadeghian S, Shirazi MH, Sarafnejad A, Fazeli MR, Amin GH, et al. Survey of anti-bacterial effect of plant extracts (Fennel-Dill-Caraway-Cinnamon) by flow cytometry and disk diffusion. avicenna J Clin Med. 2004;11(3):42-7. [Persian].

4. Darvish S, Khataminejad MR. Comparison of the invasive pathological method and serological diagnosis of Helicobacter pylori in patients at Taleghani hospital in Chalous from 2014- 2015. Iran J Med Microbiol. 2016;10(3):61-7. [Persian].

5. Shoae Hassani A, Hamdi K, Ordouzadeh N, Ghaemi A, Mohmmadi I. Inhibitory Effect of Green and Black Teas Ethyl acetate extracts on Helicobacter pylori the causative agent of peptic ulcers. J Qazvin Univ Med Sci. 2010;13(4):12-8. [Persian].

6. Obleagă CV, Vere CC, Vâlcea ID, Ciorbagiu MC, Moraru E, Mirea CS. Helicobacter pylori: types of diseases, diagnosis, treatment and causes of therapeutic failure. J Mind Med Sci. 2016;3(2):150-61.

7. Kaboli SA, Garmrudi B, Roshanaei G, Majlesi A, Khalilian A, Aghajanimir MS. Comparison of sequential regimen and standard therapy for Helicobacter pylori eradication in patients with dyspepsia. Avicenna Journal of Clinical Medicine. 2013;20(3):184-93. [Persian].

8. Megraud F, Coenen S, Versporten A, Kist M, Lopez-Brea M, Hirschl AM, et al. Helicobacter pylori resistance to antibiotics in Europe and its relationship to antibiotic consumption. Gut. 2013;62(1):34-42. doi: 10.1136/gutjnl-2012-302254.

9. O'Mahony R, Al-Khtheeri H, Weerasekera D, Fernando $\mathrm{N}$, Vaira D, Holton J, et al. Bactericidal and antiadhesive properties of culinary and medicinal plants against Helicobacter pylori. World J Gastroenterol. 2005;11(47):7499-507. doi: 10.3748/wjg.v11.i47.7499.

10. Robles-Zepeda RE, Velázquez-Contreras CA, GaribayEscobar A, Gálvez-Ruiz JC, Ruiz-Bustos E. Antimicrobial activity of Northwestern Mexican plants against Helicobacter pylori. J Med Food. 2011;14(10):1280-3. doi: 10.1089/jmf.2010.0263.

11. Asha MK, Debraj D, Prashanth D, Edwin JR, Srikanth HS, Muruganantham N, et al. In vitro anti-Helicobacter pylori activity of a flavonoid rich extract of Glycyrrhiza glabra and its probable mechanisms of action. J Ethnopharmacol. 2013;145(2):581-6. doi: 10.1016/j.jep.2012.11.033.

12. Salam R, Sarker BK, Haq MR, Khokon JU. Antimicrobial activity of medicinal plant for oral health and hygiene. Int J Nat Soc Sci. 2015;2(1):1-12.

13. Amoian B, Noori Bayat SH, Molana Z, Moghaddam Nia AA, Asgharpoor F. Assessment of antibacterial effect of cinnamon on growth of Porphyromonas gingivalis from chronic periodontitis patients with deep pockets (in vitro). J Dent Med. 2014;27(1):8-15. [Persian].

14. Gunawardena D, Karunaweera N, Lee S, van Der Kooy F, Harman DG, Raju R, et al. Anti-inflammatory activity of cinnamon (C. zeylanicum and C. cassia) extracts identification of E-cinnamaldehyde and o-methoxy cinnamaldehyde as the most potent bioactive compounds. Food Funct. 2015;6(3):910-9. doi: 10.1039/c4fo00680a.

15. Rao PV, Gan SH. Cinnamon: a multifaceted medicinal plant. Evid Based Complement Alternat Med. 2014;2014:642942. doi: 10.1155/2014/642942.

16. Perri F, Qasim A, Marras L, O'Morain C. Treatment of Helicobacter pylori infection. Helicobacter. 2003;8 Suppl 
1:53-60. doi: 10.1046/j.1523-5378.2003.00162.x.

17. Homayoni F. Evaluation of the effect of Cinnamon on Helicobacter pylori infection [dissertation]. Qazvin: Qazvin Univ Med Sci; 2015. [Persian].

18. Camargo MC, Piazuelo MB, Mera RM, Fontham ET, Delgado AG, Yepez MC, et al. Effect of smoking on failure of $\mathrm{H}$. pylori therapy and gastric histology in a high gastric cancer risk area of Colombia. Acta Gastroenterol Latinoam. 2007;37(4):238-45.

19. Silva FM, Zaterka S, Eisig JN, Chehter EZ, Chinzon D, Laudanna AA. Factors affecting Helicobacter pylori eradication using a seven-day triple therapy with a proton pump inhibitor, tinidazole and clarithromycin, in Brazilian patients with peptic ulcer. Rev Hosp Clin Fac Med Sao Paulo. 2001;56(1):11-6. doi: 10.1590/S0041-87812001000100003.

20. Nir Y, Potasman I, Stermer E, Tabak M, Neeman I. Controlled trial of the effect of cinnamon extract on Helicobacter pylori. Helicobacter. 2000;5(2):94-7. doi: 10.1046/j.1523-5378.2000.00014.x.

21. Sujatha M, Victorathisayam T. Differential antibacterial and antioxidant activity of spices against some common pathogens. Global J Mod Biol Tech. 2012;2(2):58-67.

22. Kumar EES, Jabbar MA. Taxonomic Status of Cinnamomum alexei (Lauraceae). J Sci Res. 2014;6(2):395-7. doi: 10.3329/ jsr.v6i2.17091.

23. Hong JW, Yang GE, Kim YB, Eom SH, Lew JH, Kang H. Anti-inflammatory activity of cinnamon water extract in vivo and in vitro LPS-induced models. BMC Complement Altern Med. 2012;12:237. doi: 10.1186/1472-6882-12-237.

24. Durak A, Gawlik-Dziki U, Pecio L. Coffee with cinnamon - impact of phytochemicals interactions on antioxidant and anti-inflammatory in vitro activity. Food Chem. 2014;162:81-8. doi: 10.1016/j.foodchem.2014.03.132.

25. Zaidi SF, Muhammad JS, Shahryar S, Usmanghani K, Gilani $\mathrm{AH}$, Jafri W, et al. Anti-inflammatory and cytoprotective effects of selected Pakistani medicinal plants in Helicobacter pylori-infected gastric epithelial cells. J Ethnopharmacol. 2012;141(1):403-10. doi: 10.1016/j.jep.2012.03.001.

26. Shafaghi-Asl SK, Nourizadeh E, Ghasemi Garmi KA, Maloofi N. Comparison of the effect of water and ethanol extracts of tumeric and cinnamon on the in-vitro growth of Helicobacter pylori. J Sabzevar Univ Med Sci. 2005;12(3):17-21. [Persian].

27. Pakbaz Z, Shirazi MH, Ranjbar R, Pourmand MR, Khalifeh Gholi M, Aliramezani A, et al. Frequency of sabA gene in Helicobacter pylori strains isolated from patients in Tehran, Iran. Iran Red Crescent Med J. 2013;15(9):767-70. doi: 10.5812/ircmj.5044. 